\title{
Regional cerebral blood flow abnormalities in depressed patients with cognitive impairment
}

\author{
R J Dolan, C J Bench, R G Brown, L C Scott, K J Friston, R S J Frackowiak
}

\begin{abstract}
Depression with cognitive impairment, so called depressive pseudodementia, is commonly mistaken for a neurodegenerative dementia. Using positron emission tomography (PET) derived measures of regional cerebral blood flow (rCBF) a cohort of 33 patients with major depression was studied. Ten patients displayed significant and reversible cognitive impairment. The patterns of rCBF of these patients were compared with a cohort of equally depressed non-cognitively impaired depressed patients. In the depressed cognitively impaired patients a profile of rCBF abnormalities was identified consisting of decreases in the left anterior medial prefrontal cortex and increases in the cerebellar vermis. These changes were additional to those seen in depression alone and are distinct from those described in neurodegenerative dementia. The cognitive impairment seen in a proportion of depressed patients would seem to be associated with dysfunction of neural systems distinct from those implicated in depression alone or the neurodegenerative dementias.
\end{abstract}

( $¥$ Neurol Neurosurg Psychiatry 1992;55:768-773)

Primary depression with significant cognitive impairment, commonly referred to as depressive pseudodementia or the dementia of depression, may be mistaken for a progressive neurodegenerative dementia. ${ }^{1}$ Depression itself may also be a concomitant of a progressive degenerative dementia, particularly in its early phases. ${ }^{2}$ The conjunction of depression and cognitive impairment frequently poses a clinical diagnostic problem which may hamper patient management. Recognition of a primary depression masquerading as a neurodegenerative dementia is clinically important because of its treatability. Depression with cognitive impairment can lead to misdiagnosis of primary degenerative dementia even in specialist centres. ${ }^{3}$ Misdiagnosis, more common in the elderly, may also occur in the presenium. ${ }^{45}$ The extent of misdiagnosis may be inferred from a study which reported that $8 \%$ of patients with an index diagnosis of dementia were rediagnosed as depression on subsequent admission. ${ }^{6}$ Depressed patients with cognitive impairment demonstrate a significant improvement on quantitative assessments of cognition following treatment or on follow-up. ${ }^{78}$

The neurobiological basis of depression related cognitive impairment remains obscure. Distinct patterns of focal cerebral metabolic abnormalities have been described in primary depression. ${ }^{910}$ The most consistent change described is a decrease in rCBF or metabolism in the left dorsolateral prefrontal cortex (DLPFC). We report a study of depressed patients, using PET derived measures of rCBF, which reveals a profile of abnormality, distinct from that seen in depression alone, in depression related cognitive impairment.

\section{Subjects and methods}

Patients included in the study were recruited from district psychiatric services in north London and the National Hospital for Neurology and Neurosurgery. Potential participants indicating willingness to cooperate with the study and ability to give informed consent were administered The Schedule for Affective Disorders and Schizophrenia (SADS). ${ }^{11}$ Patients who met Research Diagnostic Criteria $(\mathrm{RDC})^{12}$ for major depressive disorder were considered further. Exclusion criteria were a past or present history of neurological disease, drug or alcohol abuse (based on the SADS) or any significant past medical illness. Subjects were also excluded if they scored over 4 on the Hachinski ischaemic scale. ${ }^{13}$ Patients on psychotropic medication (19 of the 33) entered the study on the hypothesis that patterns of rCBF would reflect their depressed mental state rather than medication. The study was approved by the ethical committees of all referring hospitals and by the local committee of the Hammersmith Hospital, where the scans were performed. Permission to administer ${ }^{15}$ Oxygen was granted by the Administration of Radioactive Substances Advisory Committee (ARSAC). All subjects gave informed written consent.

A total of 33 patients met entry criteria for the study. All patients had moderate to severe depression as rated on the 17 item Hamilton Rating Scale for Depression ${ }^{14}$ (range 17-32, mean $=25$ ). Cognitive function, assessed using a clinical neuropsychological battey as well as the Mini Mental State Examination (MMSE) and CAMCOG scale of the CAMDEX, showed that 10 patients had marked cognitive impairment and scored in the impaired range. Cognitive impairment was determined using cut-points of $\leqslant 25$ on the MMSE and $\leqslant 85$ on the CAMCOG. ${ }^{15} 16$ Subsequent follow up of these patients revealed a clinical course con- 
sistent with a primary depression and with significant improvements of their scores on both the MMSE and CAMCOG.

All subjects had steady state measurement of cerebral blood flow using ${ }^{15} \mathrm{O}$ as previously described. ${ }^{17}$ Studies were performed using a PET scanner (CTI Knoxville model 931-08/12 CTI PET Systems, Tennessee, USA). The physical performance of this scanner has been described elsewhere. ${ }^{18}$ Measured attenuation corrections were made with the ratio of counts in blank and transmission scans obtained using a ${ }^{68}$ Germanium ring source. Emission scans were reconstructed using a Hanning filter with a cut off frequency of 0.5 cycles per pixel. The images were zoomed by a factor of $2 \cdot 29$, resulting in an effective pixel size of $2.05 \mathrm{~mm}$ and a resolution of $8.5 \mathrm{~mm}$. All studies were performed in the supine position in a room with dimmed lights and minimal environmental noise extra to that of the scanner's cooling system. For each subject a polystyrene head mould was made which was used to ensure correct positioning in the scanner and relative head immobility. A $22 \mathrm{~g}$ teflon cannula was inserted into a radial artery after Allen's test for collateral circulation and infiltration of the skin with 1\% Marcain (Bupivicaine). The subjects were aligned in the scanner with reference to a laser beam system so that the detectors were parallel to the orbitomeatal (OM) line. ${ }^{15} \mathrm{Oxy}$ gen was administered by inhalation via a light plastic face mask surrounded by a clear perspex extractor hood. For the estimation of $\mathrm{CBF}$ and $\mathrm{CMRO}_{2}$ subjects inhaled $\mathrm{C}^{15} \mathrm{O}_{2}$ $(0.75 \mathrm{MBQ} / \mathrm{ml}$, flow rate $500 \mathrm{ml} / \mathrm{min}$ for 18 minutes) and ${ }^{15} \mathrm{O}_{2}(2.0 \mathrm{MBQ} / \mathrm{ml}$, flow rate 500 $\mathrm{ml} / \mathrm{min}$ for 18 minutes) respectively. Three arterial blood samples were taken during each emission scan. These samples were centrifuged and plasma and whole blood activity measured in a well counter, cross calibrated with the PET scanner. Two arterial samples were taken for estimation of Haemoglobin, $\mathrm{pACO}_{2}$ and $\mathrm{pAO}_{2}$. Blood gas estimation was undertaken in all subjects but revealed no difference between patient groups in $\mathrm{pACO}_{2}$.

Image analysis was performed on a SUN 3/60 Workstation (Sun Microsystems Europe, Surrey, UK) using an interactive image analysis software package (ANALYZE, Biodynamic Research Unit, Mayo Clinic, Rochester, $M N$, USA). The functional images were checked for artifacts and corrected for yaw and roll. The 15 original planes of data $(6.75 \mathrm{~mm}$ interplane distance) were bilinearly interpolated to 26

Table 1 Demographic features of patients studied

\begin{tabular}{|c|c|c|c|c|}
\hline & $\begin{array}{l}\text { Cognitively Impaired } \\
\text { mean }(S D)\end{array}$ & $\begin{array}{l}\text { Cognitively Unimpaired } \\
\text { mean }(S D)\end{array}$ & $t$ & $p$ \\
\hline $\begin{array}{l}\text { Number } \\
\text { Age, mean (SD) } \\
\text { Years Education mean (SD) } \\
\text { HAM-D, mean (SD) } \\
\text { MADRS, mean (SD) } \\
\text { Illness duration, wks mean (SD) }\end{array}$ & $\begin{array}{l}10 \\
60 \cdot 9(7 \cdot 8) \\
10 \cdot 1(2 \cdot 2) \\
25 \cdot 7(4 \cdot 2) \\
31 \cdot 8(5 \cdot 0) \\
45 \cdot 0(40)\end{array}$ & $\begin{array}{l}10 \\
53 \cdot 2(14 \cdot 8) \\
12.9(3 \cdot 8) \\
24 \cdot 4(3 \cdot 5) \\
29 \cdot 0(6 \cdot 4) \\
21.0(24)\end{array}$ & $\begin{array}{l}1.46 \\
2.01 \\
0.75 \\
1.09 \\
1.64\end{array}$ & $\begin{array}{l}0 \cdot 16 \\
0 \cdot 06 \\
0 \cdot 46 \\
0 \cdot 29 \\
0 \cdot 12 \\
p\end{array}$ \\
\hline $\begin{array}{l}\text { Bipolar/Unipolar } \\
\text { Medication }+1- \\
\text { Sex }(m / f)\end{array}$ & $\begin{array}{l}1 / 9 \\
8 / 2 \\
4 / 6\end{array}$ & $\begin{array}{l}1 / 9 \\
4 / 6 \\
8 / 2\end{array}$ & & $\begin{array}{l}1 \\
0.639 \\
0.639\end{array}$ \\
\hline
\end{tabular}

fFisher exact test, two-tailed. planes in a standard stereotactic space. ${ }^{19}$ Scans were analysed according to a previously described model in which regional changes in CBF are assumed to be independent of global changes. ${ }^{20}$ Global changes in blood flow across subjects were removed on a pixel by pixel basis using an analysis of covariance (ANCOVA). Following normalisation of rCBF values, to an arbitrary mean $(50 \mathrm{ml} / \mathrm{dl} / \mathrm{min})$, categorical comparisons of grouped averaged normalised scans were performed on a pixel by pixel basis. In this way a statistical parametric map (SPM) was obtained for all planes of the images for which there were adequate data. An SPM can be viewed as an image of change significance and, for categorical data, involves a comparison of group means, using the $t$ statistic, to express the significance of the differences between groups. ${ }^{21}$ This stage of the data analysis computes a $t$ value for every pixel, with significant pixels being projected in the form of an SPM. The level of significance was set to a threshold of $p<0.05$ per plane and took into account multiple comparisons using a Bonferroni like correction for the number of pixels analysed. This correction corresponded to an expected false positive rate of 1 comparison per 20 planes. $^{22}$

\section{Results}

Patients were subdivided into two groups on the basis of their scores on the MMSE, comprising those with scores $\geqslant 29(n=10)$ and those with scores $\leqslant 25(n=10)$. Those with intermediate scores were excluded from further analysis. All of the patients impaired on the MMSE scored $<85$ on the CAMCOG. This subdivision generated two groups of patients with and without cognitive impairment respectively. The two groups did not differ significantly for demographic features and medication status. Similarly the groups were matched for severity of depression, so ensuring experimental control over the variance in rCBF due to depression itself (table 1).

Comparison of depressed patients with and without cognitive impairment

A comparison was made of the rCBF profiles of depressed patients with and without cognitive impairment and an SPM was generated (fig 1). The (SPM), Bonferroni corrected, identified two distinct foci of significant change, with decreases and increases in rCBF, in the depressed cognitively impaired group. The decreases in rCBF were confined to the left medial prefrontal gyrus (BA10) and extended across 4 planes $(0 \mathrm{~mm},+4,+8$ and +12 with reference to the AC-PC line). The significant increases in $\mathrm{rCBF}$ were centred to the right of the cerebellar vermis and extended across 3 planes $(-12 \mathrm{~mm},-8$ and -4$)$. The rCBF values and the coordinates of the most significant pixel locations are shown in table 2 . The rCBF values at these pixel locations are shown as scatterplots in fig 2 .

The two groups (impaired and nonimpaired) differed, though non-significantly, in 


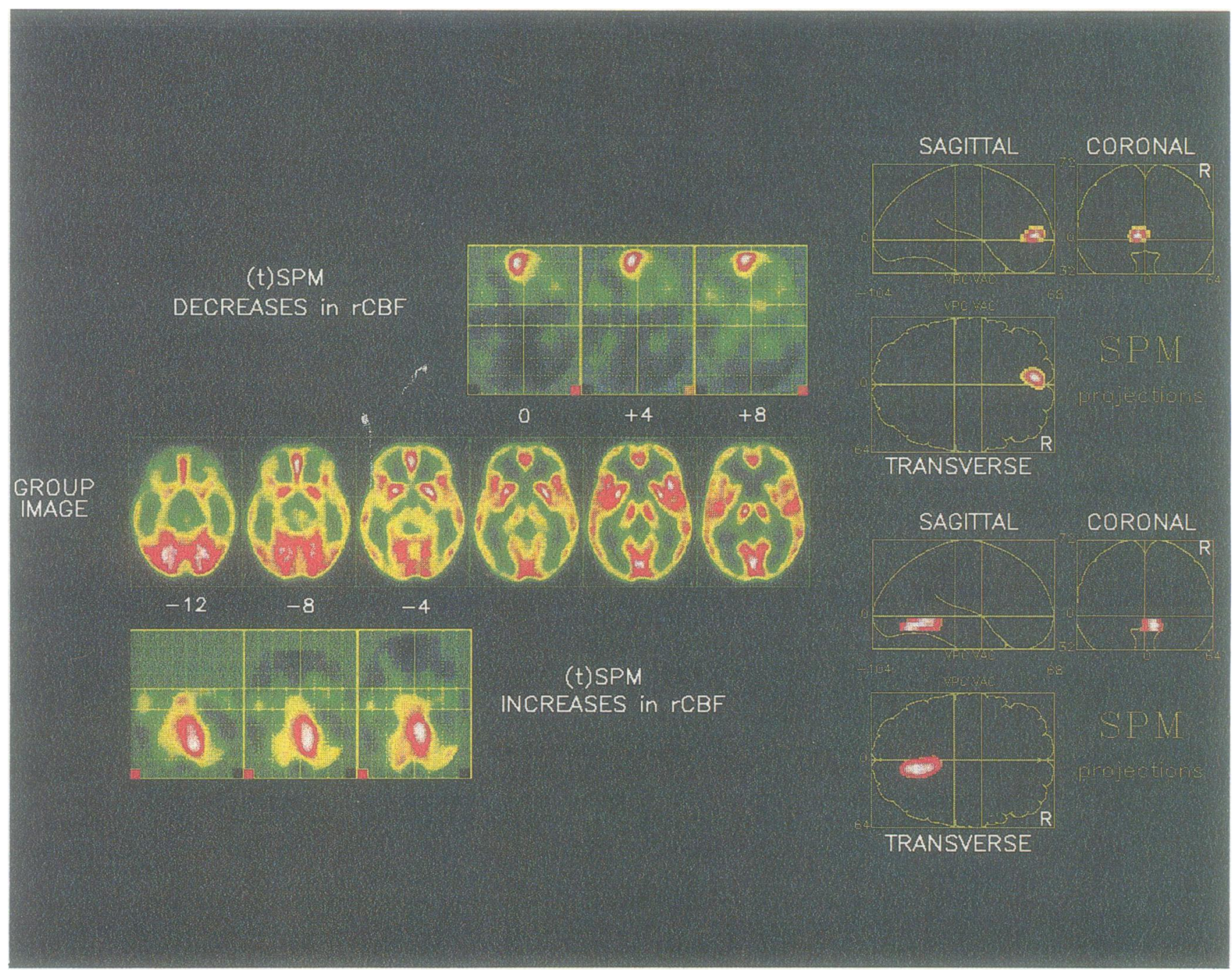

Figure 1 Statistical maps showing significant changes in cerebral blood flow between the two groups, depressed patients with and without cognitive impairment. Maps are shown both as transverse slices in which red and white areas exceed the criterion for significance $(p<0.05)$ and as projections onto coronal, sagittal and transverse views of the brain in which every pixel displayed is significant $(p<0.05)$; the group image shows the relevant transverse slices of averaged scans from 20 normal volunteers and is presented to allow reference to normal anatomy.

terms of medication status with more of the impaired group taking psychotropics. The medication details of both groups are presented in table 3. To examine the possible effects of medication on rCBF we examined the total cohort of patients and compared medicated $(n=19)$ with unmedicated $(n=14)$ patients in terms of rCBF. This comparison failed to identify any foci of significant change even at a lower threshold of significance than that utilised in the comparison of cognitively impaired with non-impaired patients.

Table 2 Coordinates of the pixels where the most significant differences in blood flow were identified. The reference stereotaxic atlas is that of Talairach and Tournoux. ${ }^{19}$ The $C B F$ values are in units of $\mathrm{ml} / \mathrm{dl}$ tissue $/ \mathrm{min}$, and have been adjusted for a global mean blood flow of $50 \mathrm{ml} / \mathrm{dl} / \mathrm{min}$.

\begin{tabular}{|c|c|c|c|c|c|}
\hline \multirow[b]{2}{*}{ Location } & \multicolumn{3}{|c|}{ Co-Ordinates } & \multirow{2}{*}{$\begin{array}{l}\text { Regional } C B F \\
\text { Impaired }\end{array}$} & \multirow[b]{2}{*}{ Unimpaired } \\
\hline & $x$ & $y$ & $z$ & & \\
\hline Cerebellar Vermis & $\begin{array}{r}-8 \\
-6 \\
-6 \\
-6 \\
8 \\
10 \\
8\end{array}$ & $\begin{array}{r}48 \\
52 \\
54 \\
54 \\
-66 \\
-60 \\
-48\end{array}$ & $\begin{array}{r}0 \\
4 \\
8 \\
12 \\
-12 \\
-8 \\
-4\end{array}$ & $\begin{array}{l}57 \cdot 3 \\
55 \cdot 1 \\
51 \cdot 4 \\
50 \cdot 1 \\
81 \cdot 6 \\
78 \cdot 3 \\
68 \cdot 1\end{array}$ & $\begin{array}{l}62 \cdot 6^{\star \star} \\
60 \cdot 2^{\star \star} \\
56 \cdot 2^{\star \star} \\
54 \cdot 1^{\star \star} \\
72 \cdot 7^{\star \star} \\
70 \cdot 0^{\star \star} \\
61 \cdot 7^{\star \star}\end{array}$ \\
\hline
\end{tabular}

$\star \star p<0.05$ Bonferroni corrected.
A non significant trend was evident for the cognitively impaired and non impaired groups to differ in terms of illness duration and years of education. The possible effects of these two variables on $\mathrm{rCBF}$ at the two major loci, medial prefrontal and ceebellar vermis, was therefore assessed in a correlation analysis. No significant effects of either of these two variables on rCBF were evident from this analysis.

Comparison of cognitively impaired depressed patients with normal control subjects

The ten patients with cognitive impairment were compared with normal control subjects in terms of rCBF. This analysis was carried out to determine whether deficits, additional to those identified in the comparison of cognitively impaired and non-impaired depressed patients, attributable to the presence of depressed mood, could be identified. The SPM identified areas of decreased rCBF in the left dorsolateral prefrontal cortex (DLPFC) (BA 46), the right dorsolateral prefrontal cortex (BA 46), the left anterior cingulate gyrus (BA 32) and the right insula. The SPM for this analysis is shown in fig 3 . 
Figure 2 Scatterplots for the 10 subjects in each of the two groups at the two pixels of maximum significant change in the medial frontal cortex and cerebellar vermis. In certain cases patients had identical $r C B F$ values and so some of the points represent more than one patient. $\mathrm{rCBF}$ values are normalised to a global mean of $50 \mathrm{ml} / \mathrm{dl}$ tissue/min. $I=$ cognitively impaired, $U=$ Cognitively unimpaired. showing the ICBF values
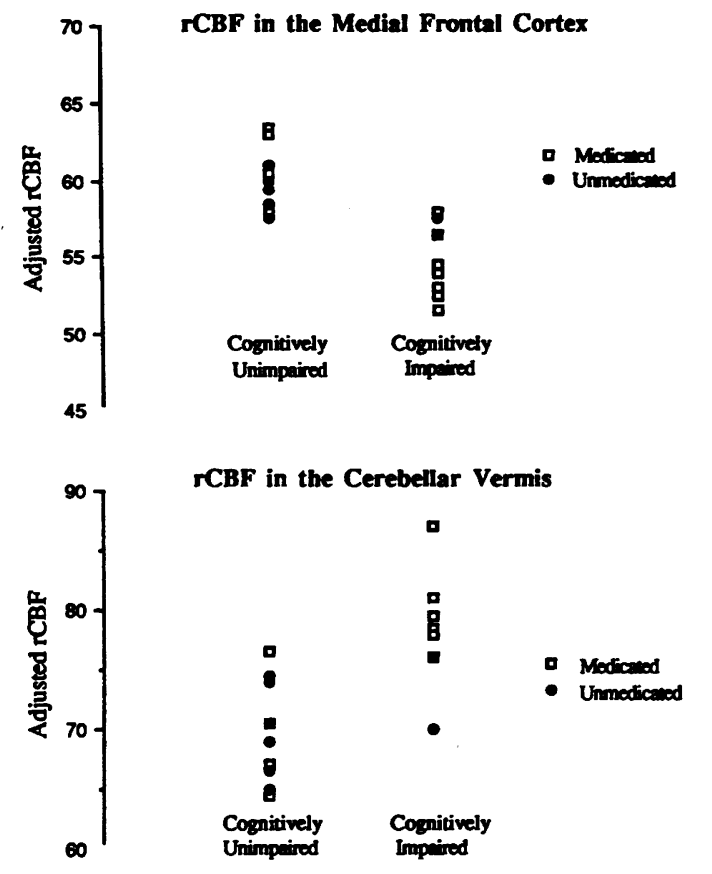

\section{Discussion}

Generalised and regional decreases in cerebral blood flow and metabolism have previously been reported in bipolar and unipolar depressed patients. ${ }^{93-26}$ The regional decreases described in depression have all involved association areas of the cortex. The most commonly reported abnormality is a decrease in rCBF and metabolism in the left dorsolateral prefrontal cortex, though regional decreases have also been described in parietal and temporal cortices. ${ }^{91027}$ The profile of altered rCBF, consisting of decreases in the left anterior medial prefrontal cortex and increases in the cerebellar vermis, described in this investigation represents a distinct pattern of abnormality to those described in depressed patients alone.

We have previously described a left prefrontal and left anterior cingulate deficit in the total depressed patient sample described in this study, compared with normal controls. ${ }^{1028}$ In this total sample of patients the medication effects on the profile of $\mathrm{rCBF}$ were considered in detail. No effects of medication could be detected at the threshold of significance used in this study. The regional changes described in this study, of depression with cognitive impairment, are clearly distinct from those previously reported findings in terms of location. The most significant pixel for the medial prefrontal

Table 3 Medication status of patients in the two groups.

\begin{tabular}{lll}
\hline Cognitive Status & Medication Status & \\
\hline Impaired (MMSE $\leqslant$ 25) & Unmedicated & $\mathbf{n}=2$ \\
& Tricyclics (TCA) & $\mathbf{n}=3$ \\
& TCA + Neuroleptics Carbamazepine & $\mathbf{n}=3$ \\
& TCA + Tryptophan + Cirbaum & $\mathbf{n}=1$ \\
& TCA + Tryptophan + Lithium & $\mathbf{n}=1$ \\
Unimpaired (MMSE $\geqslant 29)$ & Unmedicated & $\mathbf{n}=2$ \\
& Tricyclics & $\mathbf{n}=1$ \\
& Monoamine Oxidase Inhibitor & $\mathbf{n}=1$ \\
\hline
\end{tabular}

area described in our study was centred on a plane $+4 \mathrm{~mm}$ from the AC-PC line, while the most significant pixel for the anterior cingulate gyrus and the left dorsolateral prefrontal cortex were centred on planes at $+36 \mathrm{~mm}$ and +20 $\mathrm{mm}$ with respect to the AC-PC line. The medial prefrontal locus is therefore inferior in location from both these loci and separated by distances that can be clearly resolved by the PET technique. This separation is clearly illustrated in the comparison of depressed cognitively impaired patients and normal control subjects (fig 3).

The decrease in $\mathrm{rCBF}$ in the medial frontal pole appears to be the critical abnormality in depression related cognitive impairment. A post hoc analysis of the data reported in this investigation has revealed that $\mathrm{rCBF}$ decreases in this area are highly correlated with a global measure of neuropsychological function. A decrease in $\mathrm{rCBF}$ in a similar area has also been reported from a separate study within our unit of schizophrenic patients with the psychomotor poverty syndrome, which is likewise associated with impaired neuropsychological function. ${ }^{29}$ In chronic alcohol dependence a decrease in metabolism has been observed in this region with the decrease being correlated with neuropsychological impairment. ${ }^{30}$ Although no specific neuropsychological function has been attributed to the anterior medial frontal cortex this cortical region is characterised neuroanatomically by reciprocal connections with higher order association areas, particularly the dorsolateral and caudal orbitomedial prefrontal cortex. ${ }^{31}$ Therefore its functional connectivity is consistent with a role in higher cognition. Deficits in this area seem to be critical in the cognitive impairment seen in functional psychiatric disorders.

The increase in rCBF in the cerebellum was unexpected. This finding could be a non specific effect of increased arousal in this population of patients. A modulatory role for the vermal cerebellum in autonomic function is established and anatomical connections between the cerebellum and both the hypothalamus, limbic system and prefrontal cortex have been demonstrated electrophysiologically and histologically. ${ }^{32}$ Increased $\mathrm{rCBF}$ in the cerebellar vermis has been reported in a study of lactate induced panic. ${ }^{33}$ However, we have no evidence that the cognitively impaired patients under study were either more aroused or anxious than non cognitively impaired depressed patients. An alternative explanation for the findings is that the increase is directly related to the cognitive impairment. Clinical evidence points to a role for the cerebellum in emotional experience and cognition. Cerebellar pathology is associated with an increased risk for affective illness while hypoplasia of the cerebellar vermal lobules is reported in autism. ${ }^{3435} \mathrm{~A}$ role for the cerebellum in both motor planning and learning is established and imaging studies in normal subjects indicate that the cerebellum also participates in cognition. ${ }^{36-38}$ Deficits in associative learning have been described in patients with cerebellar lesions. ${ }^{39}$ The proposal of a functional reci- 
Figure 3 Statistical parametric maps showing significant $(p<0.05$ Bonferroni corrected) increases and decreases in $r C B F$ in the patients with depression related cognitive impairment compared with 23 normal control subjects. The pixels at which there is a significant change have been projected onto sagittal, coronal and transverse renderings of the standard brain volume of Talairach and Tournoux.

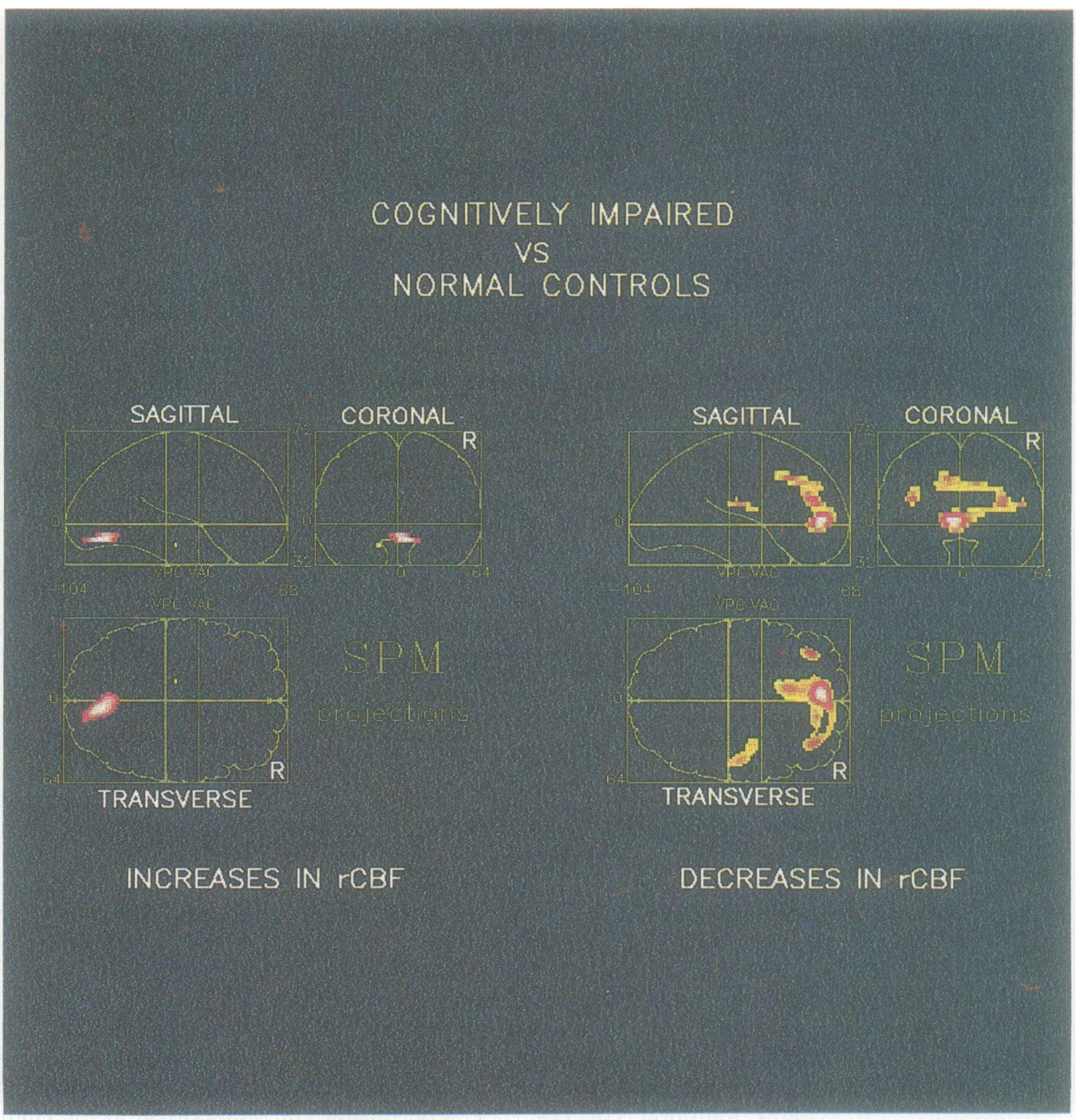

procity between the medial prefrontal cortex and the cerebellar vermis, mediated via prefrontal-cerebellar connections, in relation to cognitive function might therefore explain our findings. ${ }^{4041}$

The profile of rCBF described in this study is distinct from that seen in the more common forms of neurodegenerative dementia. In $\mathrm{Alz}$ heimer's type dementia the typical pattern of rCBF and metabolic abnormalities are posterior in location, symmetrical in distribution, with an emphasis on the inferior parietal and posterior superior temporal cortical areas. ${ }^{42}$ The cognitive impairments seen in dementia of the Alzheimers type and those seen in primary depressive illness may be due to dysfunction in separate neuroanatomical systems. In the less common frontal type neurodegenerative dementias decreases in rCBF have been described, but these are bilateral and more extensive than the pattern described in this study. We would, however, caution against an interpretation of our findings that might suggest a possible clinical role in differential diagnosis. We have no information on the specificity or sensitivity of the findings. The mean age of our sample is of course considerably younger than that of typical patients with neurodegenerative types of dementia. It is also important to bear in mind that the changes we describe are additional to those that underlie depression itself. The patients described in our present study have been reinvestigated at a minimum of one year following index assessment with most showing recovery from depression and none showing a deterioration in cognitive function. This suggests that a simple longitudinal clinical assessment of patients with depression and cognitive impairment is sufficient in most cases to clarify diagnosis. The findings of our investigation can, however, be interpreted as implicating a focal disturbance in the left medial prefrontal cortex as critical in the cognitive impairment of depression.

1 Kiloh LG Pseudo-Dementia Acta Psychiat Scand 1961;37:336-50.

2 Reding M, Haycox J, Blass J. Depression in Patients Referred to a Dementia Clinic. Arch Neurol 1985; 42:894-6.

3 Marsden CD, Harrison MJG. Outcome of Investigation of Patients vith Presenile Dementia. BMF 1972;2:249-52.

4 Nott PN, Fleminger JJ. Pre senile Dementia: The Difficulties of Early Diagnosis. Acta Psychiatr Scand 1975;51:210-17

5 Ron MA, Toone BK, Garralda ME, Lishman WA. Diagnostic Accuracy in Presenile Dementia. Br $\mathcal{F}$ Psychiatry 1979;134:161-8.

6 Kendell RE. The Stability of Psychiatric Diagnoses. Br 7 Psychiatry 1974;124:352-6.

7 Folstein MF, McHugh PR. Dementia Syndrome of Depression. In: Katzman R, et al, eds. Alzheimer's disease: senile dementia and related disorders (Aging, Vol 7). New York: 
Raven Press, 1978:87-93.

8 Rabins PV, Merchant A, Nestadt G. Criteria for Diagnosing Reversible Dementia Caused by Depression: Validation by 2 year Follow up. Br $\mathcal{F}$ Psychiatry 1984;144:488-92.

9 Baxter LR, Schwart JM, Phelps ME, et al. Reduction of Prefrontal Cortex Metabolism Common to Three Types of Depression. Arch Gen Psychiatry 1989;46:243-50.

10 Bench CJ, Dolan RJ, Friston KJ, Brown R, Scott L, Frackowiak RSJ. The anatomy of melancholia: a positron Frackowiak RSJ. The anatomy of melancholia: a positron emission tomography study of prima
chological Medicine 1992;3:602-15.

11 Endicott J, Spitzer RL. A Diagnostic Interview. The Schedule for Affective Disorders and Schizophrenia. Arch Gen Pychiatry 1978;35:837-44.

12 Spitzer RI, Endicott J, Robins E. Research Diagnostic criterio for a selected group of functional disorders. New York Biometrics Research Division, New York State Psychiatric Institute, 1977

13 HachinskiVC, Iliff LD, Zilhka E, et al. Cerebral Blood Flow in Dementia. Arch of Neurol 1975;32:632-7.

14 Hamilton M. A rating scale for depression. I Neuro Neurosurg Psychiatry 1960;23:56-62.

15 Roth M, Tym E, Mountioy CQ et al. CAMDEX: a standardised instrument for the diagnosis of mental disorder in the elderly with special reference to the early detection of dementia. Br $\mathfrak{J}$ Psychiatry detection of $1986 ; 149: 698-709$.

16 Folstein MF, Folstein SE, McHugh PR. "Mini Mental State". I Psychiatr Res 1975;12:189-98.

17 Frackowiak RSJ, Lenzi G-L, Jones T, Heather JD. Quantitative Measurement of Regional Cerebral Blood Flow and Oxygen Metabolism in Man Using 150 and Positron Emission Tomography: Theory, Procedure, and Norma Values. $f$ Comp Ass Tomog 1980;4(6):727-36.

18 Spinks TJ, Jones T, Gilardi MC, Heather JD. Physical Performance of the Latest Generation of Commercia Positron Scanner. IEEE Trans Nucl Sci 1988;35:721-5.

19 Talairach J, Tournoux P. Co-Planar stereotaxic atlas of the human brain. Stuttgart: George Thieme Verlag, 1988:1-122.

20 Friston $\mathrm{KJ}$, Frith CD, Liddle PF, Dolan RJ, Lammertsma AA, Frackowiak RSJ. The relationship between global and local changes in PET scans. 7 Cereb Blood Flow Metab $1990 ; 10: 458-66$.

21 Friston KJ, Frith CD, Liddle PF, Frackowiak RSJ. Comparing functional (PET) Images: The assessment of significant change. If Cereb Blood Flow Metab 1991 11:690-9.

22 Bailey DL, Jones T, Friston KJ, Frackowiak RSJ. Physica validation of statistical parametric mapping. $\Im$ Cereb Blood Flow Metab 1991;11:2 (S150)

23 Mathew RJ, Meyer JS, Francis DJ, Semchuk KM, Mortel $\mathrm{K}$, Clagorn JL Cerebral Blood Flow in Depression. Am f Psychiatry 1980;137:1449-50.

24 Warren LR, Butler RW, Katholi CR, McFarland CE, Crews EL, Halsey JH Jr. Focal Changes in Cerebral Blood Flow Produced by Monetary Incentive During a Mental Produced by Monetary Incentive During a Mental Brain Cognition 1984;3:71-85.

25 Gur RE, Skolnick BE, Gur RC, et al. Brain Function In
Psychiatric Disorders. 2. Regional Cerebral Blood Flow in Medicated Unipolar Depressives. Arch Gen Psychiatry 1984;41:695-9.

26 Sackeim HA, Prohovnik I, Moeller JR, et al. Regional Cerebral Blood Flow in Mood Disorders. 1. Comparison of Major Depressives and Normal Controls at rest. Arch Gen Psychiatry 1990;47:60-70.

27 Post RM, DeLisi LE, Holcomb HH, Uhde TW, Cohen R, Buchsbaum MS. Glucose Utilization in the Temporal Cortex of Affectively Ill Patients: Positron Emission Tomography. Biol Psychiatry 1987;22:545-53.

28 Bench CJ, Dolan RI, Friston KJ, Scott L Brown RG, Frackowiak RSJ. Regional cerebral blood flow in depresFrackowiak RSJ. Regional cerebral blood flow in depression measured with positron emission tomography. $f$

29 Liddle PF, Friston KJ, Hirsch SR, Frackowiak RSJ. Regional Cerebral Metabolic Activity in Chronic Schizophrenia. Schiz Res 1990;3:23-4.

30 Gilman S, Adams K, Koeppe RA, et al. Cerebellar and Frontal Hypometabolism in Alcoholic Cerebellar Degeneration Studied with Positron Emission Tomography. Ann Neurol 1990;28:775-85.

31 Jacobson S, Trojanowski J. Prefrontal granular cortex of the rhesus monkey. 1. Intrahemispheric cortical afferents. Brain Res 1977;132:209-33.

32 Heath RG, Harper JW. Ascending projections of the cerebellar fastigial nucleus to the hippocampus, amygdala, and other temporal lobe sites: Evoked potential and histological studies in monkeys and cats. Exp Neurol histological studies

33 Reiman EM, Raichle ME, Robins E, et al. Neuroanatomical Correlates of a Lactate-Induced Anxiety Attack. Arch Gen Psychiatry 1989;46:493-500.

34 Lippmann S, Manshadi M, Baldwin H, Drasin G, Rice J, Alrajeh S. Cerebellar Vermis Dimensions on Computerized Tomographic Scans of Schizophrenic and Bipolar Patients. Am Psychiatry 1982;139:667-8.

35 Courchesne E, Yeung-Courchesne R, Press MD, Hesselink JR, Jermgan TL. Hypoplasia of cerebellar vermis lobules $\mathrm{VI}$ and VII in autism. $N$ Engl $f$ Med 1988;318:1349-54.

36 Ito $M$. The cerebellum and motor control. New York: Raven, 1984.

37 Decety J, Sjoholm H, Stenberg G, Ingvar D. The cerebellum participates in mental activity: tomographic measurements of regional cerebral blood flow. Brain Res 1990;535:313-7.

38 Watson PJ. Nonmotor functions of the cerebellum. Psychol Bull 1978;5:944-67.

39 Bracke-Tolmitt R, Linden A, Canavan GM, et al. The cerebellum contributes to mental skills. Behav Neurosci 1989;103:442-6.

40 Leiner HC, Leiner AL, Dow RS. Does the cerebellum contribute to mental skills? Behav Neurosci 1986; 100:443-54.

41 Sasaki K. Cerebro-cerebellar interconnections in cats and monkeys. Amsterdam: Elsevier, 1979:105-24.

42 Frackowiak RSJ, Pozzilli C, Legg NJ, et al. Regional Cerebral Oxygen Supply and Utilization In Dementia. A Clinical And Physiological Study With Oxygen-15 And Positron Tomography. Brain 1981;104:753-78. 